\title{
The Tibetan Ethnic Enclave in New Delhi a Visual Perspective
}

\author{
Fabienne Le Houérou \\ Cnrs, Iremam, Aix-Marseille Université, Aix-en-Provence, France \\ Email: lehouerou. fabienne40@gmail.com
}

How to cite this paper: Le Houérou, F. (2018). The Tibetan Ethnic Enclave in New Delhi a Visual Perspective. Sociology Mind, 8, 203-220.

https://doi.org/10.4236/sm.2018.83016

Received: December 12, 2017

Accepted: May 18, 2018

Published: May 21, 2018

Copyright $\odot 2018$ by author and Scientific Research Publishing Inc. This work is licensed under the Creative Commons Attribution International License (CC BY 4.0).

http://creativecommons.org/licenses/by/4.0/

\begin{abstract}
This article aims to explore the Tibetan Diaspora in India in one site. We will focus on Majnu Ka Tilla in New Delhi. This paper is based on an inquiry driven qualitative study. It will not give a total and exhaustive vision of the entire refugee population in Majnu Ka Tilla but will offer selected testimonies chosen for their high heuristic value to explore the connection between space and its social construction by the refugees highlighting the notion of "ethnic enclave" (Portes \& Wilson, 1980). The narratives collected are genderly oriented as we selected feminine narrations related to the representation of space. We will discuss the heuristic value of visual methodologies such as photography, auto-photography, photovoice and participant camera. Two documentaries were shot in 2008 and 2011 in the Tibetan Diaspora in India focusing on gender issues and the place of women inside the Tibetan community (Le Houérou, 2008, 2014). These non broadcasted and non-commercial movies with an ethnographic intention are available on line with a free access on Dailymotion (links http://www.dailymotion.com/video/xd94rf_les-sabots-roses-du-bouddha-web doc_news and: http://www.dailymotion.com/video/x2g236p). The two films are both exploring the singular position of women in the Tibetan Diaspora in India stressing on their economical activity for the first one and social marginality for the second one highlighting the notion of Tibetanness in exile in a specific location. How a location can shape a diasporic memory and collective identity?
\end{abstract}

\section{Keywords}

Tibetan, Diaspora, New Delhi, Majnu Ka Tilla, Ethnic Enclave, Photovoice, Visual Studies, Refugees, Women, Memory, Identity, Spatial Dynamic, Social Media, Research, Frontiers

\section{Introduction}

Visual methodology and visual anthropology are at the heart of the epistemo- 
logical approach of this paper. We will propose selected visions of the space and Tibetanness in a Tibetan enclave in India. We will not offer the reader a full objective representation of the Tibetans in exile. Are narrations objective? Representations of space and culture are connected to emotions and vary according to gender, social, regional and family backgrounds. We posit that memories are kept together by the Diaspora in a transparent collective memorial strategy. The political choice of "living together" in an ethnic enclave or niche, in North Delhi, offers the refugees material and immaterial links and a socio-geographical structure. The space is socially constructed as a diasporic niche offering series of bonds. The location of Majnu Ka Tilla is, in this perspective is a memorial challenge. The visual methodology is central to study the connections among space, culture and ethnic identity. With a memory embedded in a human geography.

After giving an overview of the Tibetan Diaspora in India we will depict the location of Majnu Ka Tilla where the Tibetan Diaspora is located in North Delhi. We will then insist on the visual methodologies used for studying memories in exile and discuss about the heuristic values of photovoice and autophotography compared with classical ethnographic filming. Autophotography is an attempt of self-empowerment granting the refugees' decision to frame their own reality. We will discuss if these methodologies emerged in the nineties are truly stimulating the comprehension of the complexity of the exiled situation.

In this perspective we invite the reader to visualize the two films mentioned above, directed with an ethnographic intention, in order to appreciate the visual dimension of the approach.

\section{Tibetans in India: Overview}

“According to the 'Tibetan Demographic Survey 2009' conducted by Planning Commission of Central Tibetan Administration (CTA), Dharamsala, in ten years, 1998-2009, about 9309 Tibetans have moved to Western countries. Some other source even indicates that each year around 3000 Tibetan move to Western countries. If this trend is to continue at the current rate, by the end of 2019, the total numbers of Tibetans in India will be reduced from current 94203 (TDS. 2009, CTA.) to just 64203 Tibetans (excluding new arrivals from Tibet) in India. Looking at this ever-increasing movement of Tibetans from their settlement to other places, it seems to me that what we call Tibetan refugee settlement is not really a settlement, but more like a transit camps and it is very possible that in near future that most of these settlements in India will turn into large old-age homes"...." (Rigzin, 2015).

Numbers of Tibetan refugees in India are, according to these official sources, are less than a hundred thousands of souls. The Central Tibetan Administration is the main institution that researchers mention for survey and demographic data sources. The CTA main census was conducted in 1998 and the projected population in 2007 mentioned that they should be (according to population growth)

${ }^{1}$ Tsewang Rigzin (2015), A Survey Research on Tibetan Entrepreneurs in India, MDP, Emory University, Atlanta, USA.

http://www.nyamdel.com/wp-content/uploads/2014/07/report-on-Tibetan-Entrepreneurs 
"101,242 refugees in India; Nepal 16,313; Bhutan 1883; and rest of the world 25,712 (http://tibet.net/2009/04/world-wide-demographic-survey-of-tibetans-in-exile-b egins-12-april/. In facts the real survey conducted in 2009 by the CTA revealed that they were only 94,203 Tibetans in India.

(http://tibetdata.org/projects/population/). The Tibetan administration in India classifies the Tibetan forced migration to India in three waves as reported in caricatural terms by the popular encyclopedia (see

https://en.wikipedia.org/wiki/Tibetan_diaspora). It summarizes quite grossly but truly the main chronological exodus of Tibetans in India.

The CTA classifies the Tibetan forced migration to India in three waves:

The first wave took place in 1959 during the Tibetan uprising following Chinese invasion when the 14 Th Dalai Lama and his government escaped to India to seek asylum. From 1959 to 1960, about 80,000 Tibetans followed the Dalai Lama to India through the Himalaya Mountains (International Campaign for Tibet, 2007).

The second wave of Tibetan exodus was the consequence of increasing Chinese political repression during the 1980s and the consequence of Chinese policy for widely opening Tibet to Chinese trade and tourism. During that period (1986-1996) almost 25,000 Tibetans joined their exiled community in India. This movement of refugees during this second wave is sometimes referred to as a "second exodus".

The third and current wave can be distinguished by a decline in the number of visitors and exiles, with an important number of monks and nuns. Almost 2,200 Tibetans arrived in India in 1998 most of them were monks or nuns seeking religious freedom and complete religious education. ${ }^{2}$

\section{Tibetans in Majnu Ka Tilla}

The Tibetan refugees arrived in India in 1959, the Indian Prime Minister Pandit Jawaharlal Nehru granted them asylum and they were rehabilitated in Refugee Camps across the country. Those who were not rehabilitated into these camps were settled at the plot of "Samyeling" New Aruna Nagar in New Delhi called Majnu Ka Tilla. Thus the Tibetan colony of Majnu ka Tilla developed on the banks of river Yamuna, North of Delhi on National Highway 9, covering an area of about $64,627.42$ sq mts.

The colony is divided into 12 blocks with 350 permanent registered families. An elected governing body of 7 members is directly elected by the people for a term of 3 years. The Tibetan Women association is also an elected body where we held many interviews. The Central Tibetan Administration has a permanent representative known as the Settlement Officer. The permanent population of the colony is around 3000 people (According to an Interview given to the author of this article in New Delhi 12/10/2013).

${ }^{2} 1959$ Tibetan Exodus, World Encyclopedia Heritage, available:

http://self.gutenberg.org/articles/eng/1959_Tibetan_exodus 
The Name Majnu Ka Tilla is related to the historic reign of Sikandar Lodhi (1489-1517) literally it means the hillock of Majnu, after the tilla or mound. During Delhi Sultanate, Abdulla nicknamed Majnu (crazy) a local Persian Sufi met Sikh Guru, Guru Nanak on July 20, 1505.

Majnu helped people to cross freely the Yamuna River as a service to God. In later history Sikh military leader Baghel Singh built the Majnu ka Tila Gurudwara to commemorate the stay in 1783, and the sixth Sikh guru, Guru Har Gobind who stayed there. Today it is one of oldest extant Sikh shrines in Delhi and the surrounding estate of donated by early 19th-century Sikh emperor, Ranjit Singh.

Majnu Ka Tilla area has three main residential settlements with total 3000 3500 homes, Aruna Nagar, New Aruna Nagar and Old Chandrawal village, which was came up in early 1900s, when British government settled labourers involved in the construction of the Central Secretariat buildings, during the construction of the New Delhi. The next round of settlement came post-independence in 1958-59, when Aruna Nagar was developed by the Land and Development wing of the Urban Development ministry as it disburses 925 plots of 40 sq. yard each, to people resettled here from various part of North Delhi. The Tibetan refugee camp later named New Aruna Nagar developed after 1960, and more recently two large jhuggi jhopari (hutment) clusters have developed on the periphery.

The legal status of Majnu-ka-tilla has previously come into dispute. In 1995, residents were "given a formal assurance from the Centre" that they would be allowed to remain at the site until the international dispute over Tibet was settled. In June 2006, the colony was served a court-issued notice indicating that it would be demolished in connection with the Delhi government's road expansion and Yamuna River beautification plan. At least two buildings were demolished in connection with this order. As of 2012, however, a court order had avoided eviction, regularizing the status of the colony.

The colony, officially known as New Aruna Nagar Colony, remains unauthorized though in March 2013, Government of Delhi included New Aruna Nagar (Tibetan refugee camp) in its list of 895 "to-be-regularised colonies". The refugee colony experienced widespread flooding in 2010 rainy season, as a result many of the residents took reinforcement measure in their buildings. On June 20, 2013, during the North India floods, the Yamuna River breached its banks and inundated numerous houses in the low-lying area. They remained partially submerged for several days, and people shifted to upper floors or to relief camps. The floods also lead to power outages and water shortages, raising concerns of health.

As shown in Figure 1 Majnu Ka Tilla is a well identified urban ethnic enclave in the North of the Indian capital. The citizens in New Delhi name the Tibetan niche the "Tibetan Colony" (Figure 1).

\section{Methodology}

Exploring the Tibetan community in New Delhi will lead to focus on interstitial spaces in a neighborhood in North Delhi (India) between the Tibetan Diaspora 


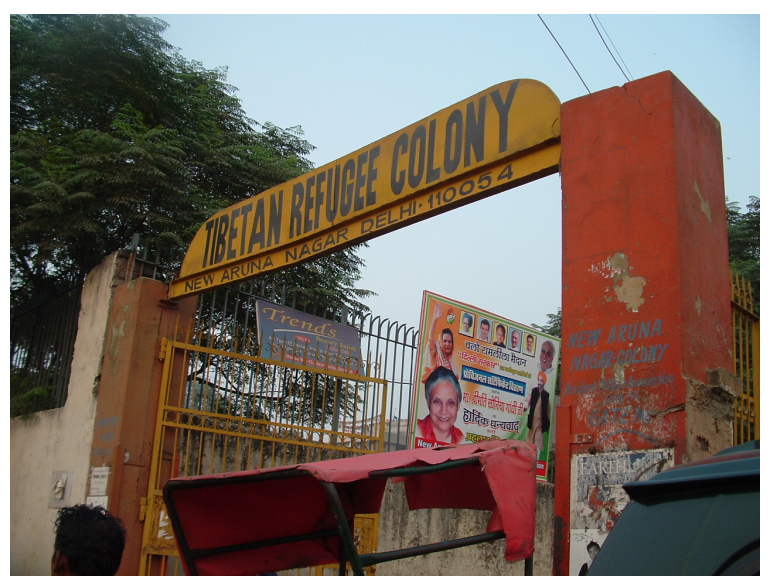

Figure 1. Picture showing the entry of the colony, credit photo Fabienne Le Houérou, 2008.

in Majnu Ka Tilla and the migrants from Punjab in Punjabi Basti. The filming methodology is at the heart of the research process using filming interactions between Tibetan refugees and Indian migrants from Punjab. We will focus on ethnic interactions and spaces of intersection where Tibetans and Punjabi, meet, coalesce, segregate or separate. The ethnographic film will highlight the "pro-filming" attitude. What we identify as "pro-filming" attitude is related to the plural ways that filmed subjects compose and fabricate their own images in front of the camera. We will raise the question of the heuristic value of disposable cameras compared to home-made smartphones videos and pictures in order to appreciate their methodological virtue. Self photographing has completely changed the images that refugees are showing and presenting of themselves. What are the significations and hypothesis of research that these new digital tools are offering? Auto-framing is leading to a shared world-wide representation of an idealized subject: active, young, handsome being the director of his own life/film. In this sense the figure of the refugee tends to participate to an enlarged homogenized ego-theater where any-body acts as the leader character of his own life picturing himself in positive contexts supposed to be posted on social networks. These posts are driving the refugee's self-representations into a fictional dimension. This paper stresses the limits of auto-photography or photo-voice methodology (Wang 1997) largely used in Human Geography and Sociology and emphasizes on the ancient tradition of ethnographic film as performing tool for describing a social group, a Diaspora an exiled culture. The outside eye being an important element of an inquiry driven research.

\section{Imaging an Enclave}

Analyzing images of a Tibetan woman on the edge in India, Angie (or Angu in Hindi) was the driver of our filmed methodology regarding the study of the Tibetan Diaspora in north India. This intended ethnographic film is available on 
Daily motion (Le Houérou, 2014)

https://docs.google.com/file/d/0BzMDmBLc5DAaNkhjNGI1dHlLaUE/edit. The visual anthropological work stands at the origin of our hypothesis and this paper aims to question the Tibetan ethnic enclave (Portes \& Wilson, 1980) and to demonstrate the high ethnic concentration of Tibetans as driver of a cultural identity and economic activity in a geographical space of Majnu Ka Tilla in New Delhi. Our approach posits that Majnu Ka Tilla can be named an ethnic enclave according to this definition. We will analyze the sociological, cultural, economical reality of this "niche" using interactions between Tibetans and Punjabi Indian sharing the urban zone in North Delhi, above Kashmere gate.

\section{Disposable Cameras}

As we mentioned in the introduction it is important to repeat that disposable cameras were offered to both communities to explore the geographical frontiers of the two migrant's communities (internal and external). Our methodological approach was inspired by many other research stressing on the heuristic dimensions of giving the migrants and refugees the opportunity to frame their own life's and their spatial interstitial spaces, their intersections, their shared spaces and their point of clear distinction and opposition. This approach was adopted in many fields in Academic Humanities, such as Geography, Sociology or Political Science. Auto-photography is largely used in Human Geography but the Anthropology stands at the origins of the methodology during the nineteen century.

It is also widely used on Migrations Studies and numbers of academic works have been impacted by the use of visual methodology. It is quite important to interpret images when working on vulnerable groups and cultural taboos. It is a major tool assisting the researcher to go beyond a traditional and somehow rigid and frozen process of questions/answers for an interactive and more inclusive dynamic. The comments of the interviewed migrants about their own visual representations of their life is named photo-voice and allows the researcher to work with the migrants (not on the migrants) in a dialogue and face-to-face interaction.

The methodology of photo-voice was originally experienced by Caroline C. Wang and Mary Ann Burris, for a study entitled Empowerment through Photo Novella: Portraits of Participation conducted in 1994 among women in a Chinese village among women. The informants had the opportunity to offer informations about their daily life and environment through photography for an entire year. Caroline C. Wang of the University of Michigan, and Mary Ann Burris, Program Officer for Women's Health at the Ford Foundation headquartered in Beijing, China advocated that images and words together could effectively express and give voice to the visions of speechless communities.

To summarize this approach we could argue that photo-voice is part of empowerment strategies giving voice (photo-voice) to marginalized communities 
and minorities, and in this perspective, adapted to research among refugees and exiles.

Giving voice to the silent subject is one of the main virtues given by this methods and it's a core argument given by the researchers using photo-voice and auto-photography. This methodology can be attractive and we observed that a collective fondness and intellectual enthusiasm could be sometimes the fruit of trend or mimicry. Mimetism exists in all human activities and research and academic is not vaccinated or spared from this type of imitation. We have also, in another hand, to stress that the invasion of smartphones on the global market with performing cameras and video taking are also at the origin of this attraction. Almost everyone takes picture all over the world. When we were working in Sudan among refugee populations, in 2000, mobile phones had already invaded one of the poorest countries in the world and we witnessed that deprived population in the Thar Desert (Rajasthan) possessed already mobile phones. In Majnu Ka Tilla in 2013 the researcher was the only one in the colony who did not possess a smartphone. This revolution of connected devices is heading to the expand of photography participating to a global culture of consumption. Images are everywhere and at the heart of global communication and connectedness. The exchange of images was never so fast, immediate that in the previous decades. We happen to follow the Tibetan colony on a daily basis just in looking at a Facebook accounts or using other social networks. Being aware simultaneously of what was going on inside the colony just using social networks.

Is this methodology of photo-voice and self-picturing valid for Migrations Studies? Rather than emphasizing on the benefits of auto-filming and auto-photography we will focus on the limits of this methodology of self fabricating images, as shown in Figures 2-7, and its "pro domo sua" logic. We will appreciate this methodology as a complementary informative strategy of research but we will question the real aptitudes of this procedure to be the core of an inquiry driven process.

Three disposables cameras were given to Tibetans refugees in Majnu Ka Tilla. The questionnaire orientation's was to "frame your life in Majnu Ka Tilla". Three of our informants were women. The study followed a gender perspective and we concentrated on Tibetan women's interviews. Women were at the center of an academic interest.

One refugee was a hair dresser particularly well-known and successful in the Tibetan colony. She was in contact with different communities and lived at the edge of the ethnic enclave. That is to say that she was closed to a major geographical point called the iron bridge. Another camera was given to a business woman manager of an important hotel in the heart of the colony. She was a very active woman and in interaction with different Indian communities and foreigners as well. The third device was offered to one of the poorest woman of the colony living at the edge of poverty. She was rather ill and her condition was at the clear margin of the colony. She was living out of marriage with an African partner and was largely object of relative discrimination by the rest of the 


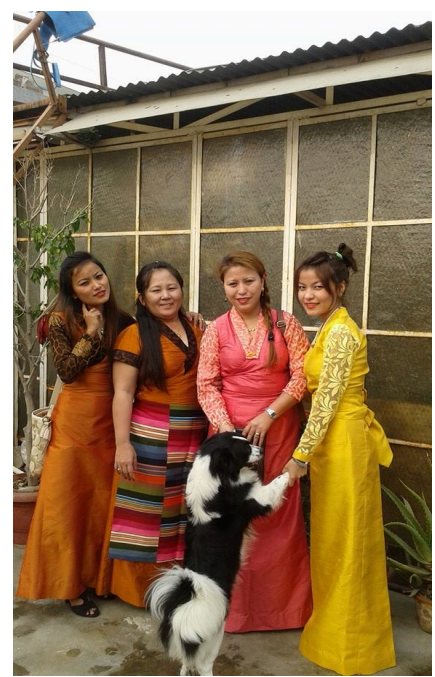

Figure 2. Traditional Tibetan silk dresses. The Tibetan cultural clothing is mainly worn during festivals. This Picture was posted on Facebook, February 2017.

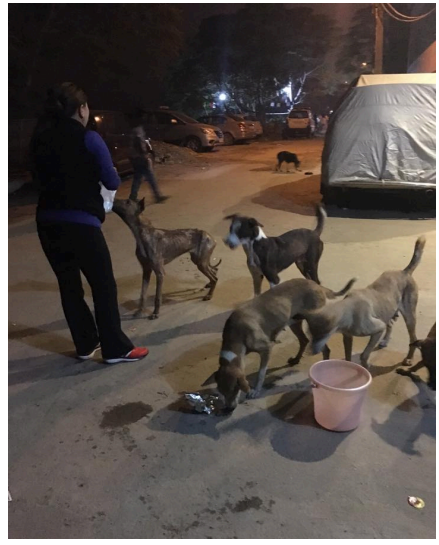

Figure 3. Is illustrating the importance of compassion for animals, especially dogs; this picture was posted on Facebook, February 2017.

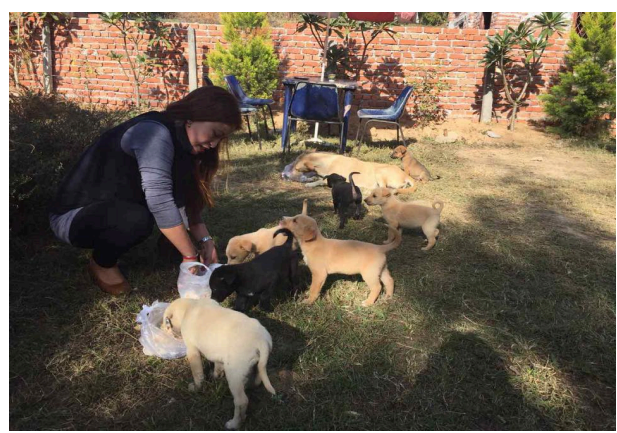

Figure 4. Is demonstrating the Tibetan care for all living sentients. Here a refugee is feeding streets dogs. Picture posted on Facebook, February 2017. 


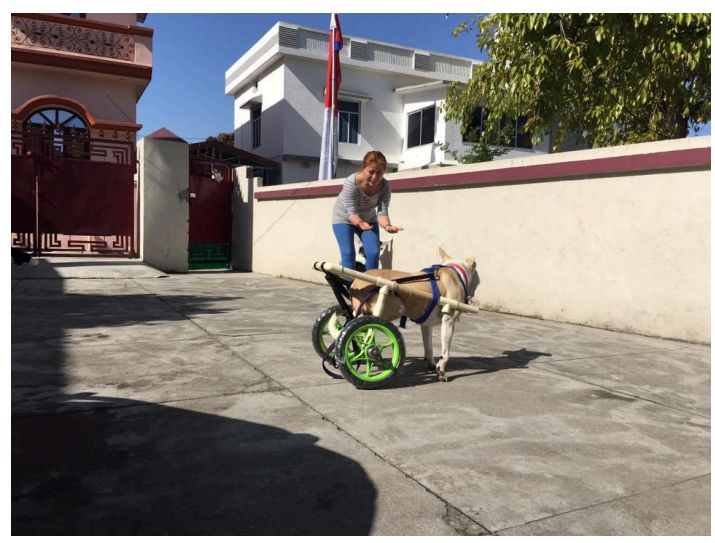

Figure 5. Picture showing a tool that the informant has invented to rescue a dog with three legs. She created this instrument for the handicapped dog. This picture demonstrates how important compassion for animals is. Posted on Facebook in December 2016.

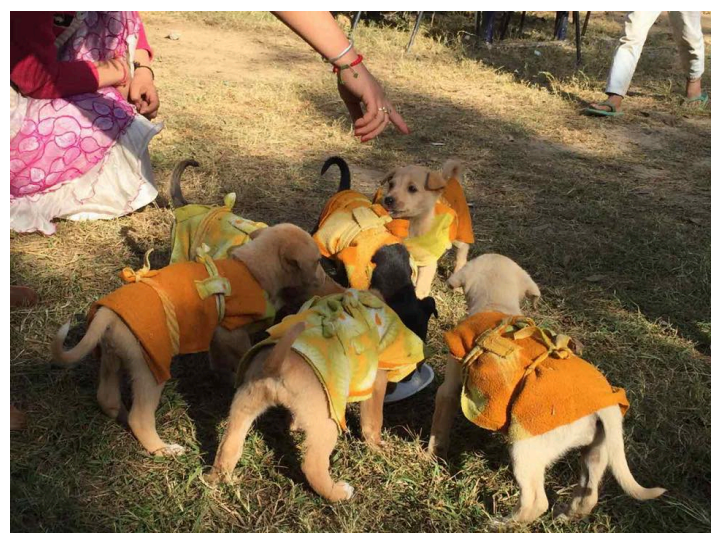

Figure 6. Is exposing the notion of compassion for animals. Here the refugee has created special sweaters for street puppies. This picture was shared on the $15 \mathrm{Th}$ December 2016 on Facebook.

Tibetan colony. These three women had different ages from 48 to 30 and came from different regions of Tibet but the three of them belonged to the second generation of refugees. They never went to Tibet (contrary to their parents) and were all three born in India. They all spoke Hindi very fluently and interacted on a daily mode with the Punjabi market out of the Tibetan colony after the most important point of intersection called the iron bridge. This bridge is considered as a spatial edge and limit tracing ethnic frontiers between the two communities as Figure 9 is bringing to view. A boundary and a link that the migrants and refugees crossed many time a day according to their businesses or activities. The Punjabi Basti is a key economical point. Most of the Tibetan restaurants and hotels are dependent on the Punjabi Basti Market for the goods and alimentary articles. Most of the circulation was a daily circulation. During the night people were not crossing the bridge. Tibetan would consider dangerous to 


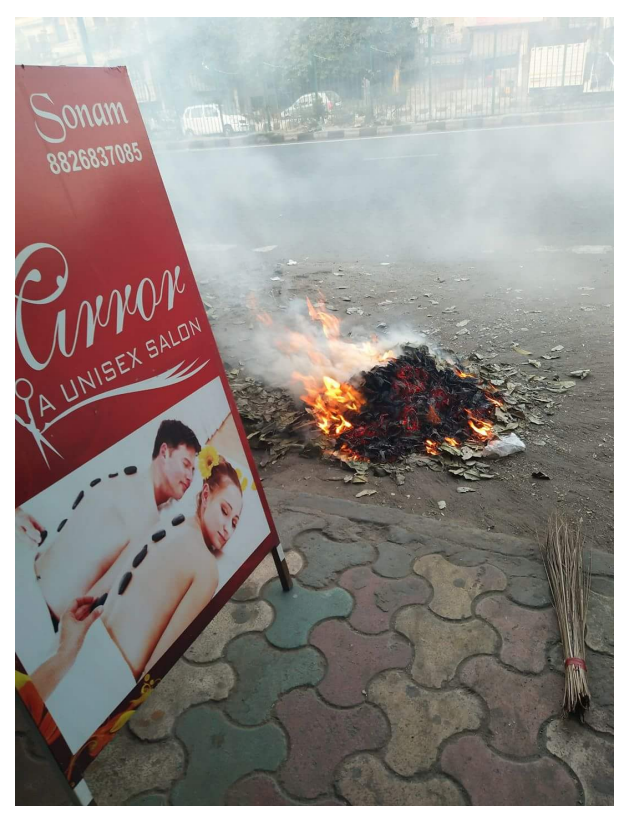

Figure 7. Evokes the hygienic duty of the refugees to keep Majnu Ka Tilla clean. The picture was posted on Facebook on the $29^{\text {th }}$ Marsh 2017.

cross it at night. Our informants were selected according to this daily circulation between the Punjabi Basti and the Tibetan enclave. The three women were crossing the line continuously for their business and activities, like most housewifes of the Tibetan colony. They gave no importance to this important bridge in their auto-photography and photovoice. Instead they gave a lot of importance to exceptional moments like Tibetan festivals. They took pictures of themselves in beautiful traditional clothes: stressing their Tibetanness. Silk dresses were at the center of their self representation and Tibetan elegance the main point of interest as the Figure 2 is exhibiting.

At a certain moment, we re-oriented our questions and asked to frame their lives with their smartphone. As we mentioned before everybody possesses a mobile phone in the Tibetan colony. The pictures taken with smartphones were similar to the photos taken with disposable cameras. Informants would wear their best clothes and go to the hairdresser and be as elegant as possible as Figure 2 is offering to the view of the reader. Even Angu (as shown in Figure 10) who was economically at the bottom of the social pyramid-as shown in Figure 10 would put her best dress and comb her hair before posing.

The second most important topic was the animals of the colony as Figures 3-6, are stressing. The business woman $\mathrm{P}$, was very religious and caring about animals and used to feed all the dogs of the colony estimating that it "was good for her karma" to take care of abandoned streets dogs.

She made many pictures of dogs: wounded dogs, sleeping dogs, eating dogs. Her everyday life was focusing on injured or miserable dogs and their protection. She was seeing dogs everywhere; in every situation she would take a picture 
of the dogs as center of her interest. This anecdotic subject is deeper than it can appear. She explained that caring about poor animals in need was part of her Karmic destiny and she would religiously explain this focus on rescuing street dogs (Figures 3-6).

The third most important frame was the street's cleaning up and the pictures will show the washing up and disinfection of the streets of the colony. The message of Figure 7 is quite clear. As explained by the informant, the picture is an invitation to clean the public space. The informant pointed and framed the dirty side of the Punjabi Basti (in Hindu Basti means village) which was the center of criticism because things were thrown everywhere and garbage was left in the middle of the road. This was the main subject of difference between "us" Tibetans and "them" the Punjabi. The Tibetans saw themselves as making all efforts for the colony to be neat. Tibetan women of the main street would clean with baskets of water the road many times a day. Figure 7 demonstrates how important it is inside the colony to have an unspoiled environment. Here our informant posted how she got read of a great amount of leafs burning them on the street nearby the bridge. The picture of Figure 7 is interestingly framed stressing on the business (beauty salon) fire (as disinfection) and a traditional Indian broom (which is used by a political party as symbol of anticorruption program). When asking my informants why she posted this picture on Facebook she would insist on everyday life keeping a healthy environment and insisting on what she did in the morning. She explained that she was starting her everyday duty with hygienic activities. The message of a purification and detox is also a very clear message sent to the clients telling them that in her beauty parlor they will find a very healthy, smooth and purified atmosphere.

The fourth subject shared by the three informants and other women of the colony, is a common interest related to cuisine and food. These pictures, as shown on Figure 8, are suggesting the large impact and influence of Indian cooking in the Diaspora. Tibetans are cooking a special cuisine but would also be very fond of "dal" and Indian spices would be largely used and appreciated. Mixity and cross-cultural exchanges are very much highlighted by a shared cooking of borrowed receipts. It emphasizes the Indian context and the "impregnation" of Indian culture in the Tibetan Diaspora everywhere in India. Cuisine's hybridity is a very popular and shared slow cultural process, too often neglected by scholars like Homi Bahba who emphasize the textual dimension of cultural hybridity (Bahba, 2004). Cooking is a powerful agent of mixity because it touches everyone especially the women of the community. Refugee women would rather picture their cooking inventions and skills than the key urban points of the colony like the huge iron bridge of Majnu Ka Tilla.

None of the three women took picture of intersection and show no interest in the Bridge presented on Figure 9. The Iron Bridge was a point of reference, a space landmark in their everyday and banal interactions. Tibetans would locate a place, behind or beyond the bridge. In the pictures they never represented the 


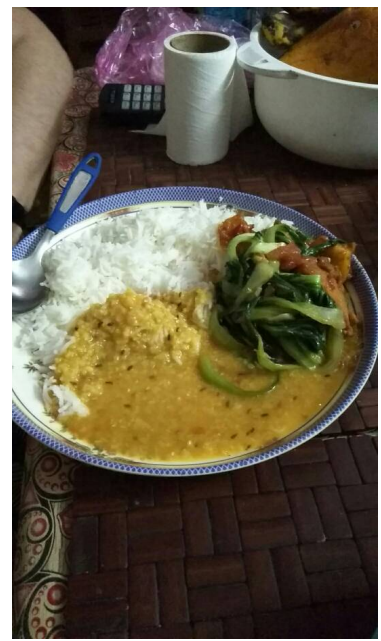

Figure 8. Exhibiting the Indian cuisine adopted by the refugees. This picture was posted on a whattapp group, 19 April 2017, Majnu Ka Tilla.

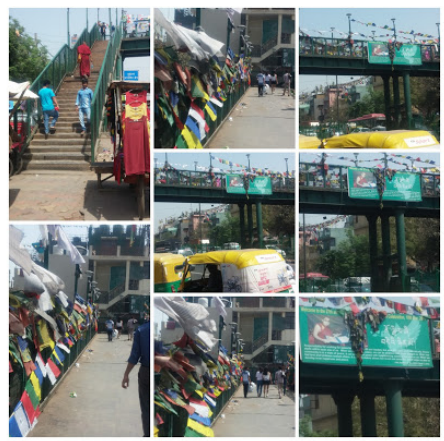

Figure 9. Offering a special view of the bridge in Majnu Ka Tilla. The connecting arch made of iron is a spatial frontier separating the Tibetan colony to the rest of the city. Giving the Diaspora a special territory well circumscribed. Credit Photo Fabienne Le Houérou.

bridge as interesting. The bridge was thus seen as trivial, ordinary, and unexceptional. In a word the bridge was just a vulgar geographical reference. They took pictures of the family, the food, the temple, the festivities but the market place and the bridge was not a center of interest.

We concluded that there is contradiction between the rational points of junction and interstitial spaces and the way the people see and represent their daily life. The bridge was just a spatial reference, fundamental for any circulation but very poorly depicted because it meant nothing on the emotional, affective, social and cultural dimension. It was neglected because it was not perceived as important for the Tibetan identity, it was exterior of Tibetanness, and it was the beginning of another world, not sufficiently significant to be mentioned. At the con- 
trary the three women would emphasize on a key notion. They picked up the concept of edges that they understood as plural. The concept of edge was built when the ethnographer took the camera and interviewed the colony about the case study of Angie. We could argue that the actual smartphone abilities to frame everyday life is today far more interesting to give voice to a community and a social group than disposal cameras. The pictures posted on Facebook or Whatapp group were much more meaningful than cameras which in 2018 look particularly outdated. Again as we stated above when the film Angu was shot in 2013 the author of this paper was the only person in the colony not to have a modern telephone but an old device incapable of internet connections. The new social networks in that perspective are revolutionary. There is no need of a researcher distributing disposal cameras for an inquiry driven ethnological process. Being connected with your field is simpler, more direct and has no interference with the presence of the researcher. Most of the times interviewed people wish to please the researcher. Analyzing social networks posts is able to offer "pure" information reducing the researcher's impact. We would suggest that disposal cameras were useful at the beginning of the nineties and could appear as a "new" approach, inspired by Wang theoretical advocacy on minorities, (Wang, 1997, 2001) but it is not the case anymore. Academic research on Migration Geography focused on photovoice arguing that it was a heuristic tool to approach vulnerable populations comprising children who were not able to explain wordly their own situations. (Fournier et al., 2014; Thomas, 2009; Wang, 1997). People don't ask permission to the researcher to post and comment their life style and interests. They would also comment their cuisine and the way they prepare food and become the ambassadors of themselves without any voice speaking for them. This direct communication is revolutionary and stresses many questions. Are subjects clearly seeing what is important in their life? Are your everyday pictures able to measure your casual life and day to day exchanges. Your post might be important in your own eyes but remains rationally insignificant at a scientific and rational level. In many ways we would observe that the interviewed subjects in Majnu Ka Tilla never stressed, highlighted or focused on the importance of the iron bridge. The bridge is a rational urban crossroad fundamental for any kind of circulation. The iron arch was thus crucial for any exchange between the Tibetan colony and the rest of the city of New Delhi (Figure 9). These observations led me to re-consider the role of the ethnographer in traditional anthropological field work.

\section{The Researcher as the Only Eye to Construct the Framed Reality}

In our visual observation the bridge was the center of the Tibetan colony in New Delhi. The bridge was an edge, as presented in Figure 9, a frontier but also a link, a connection and key junction. The notion of edge emerged when shooting the ethnographic film "Angu, a woman on the edge". Filming symbolic and casual interactions in their ordinary context was a theoretical approach inspired by 
Goffman (Goffman, 1959). The notion of edge was a concept that Angu/Angie inspired when filming her life style. Her portray exposed in Figure 10 is focusing on her marginal position. It is the most marginal actor of the field research (Angie) who happened to be the most fundamental element to comprehend the limits of Tibetan-hood. Who is Tibetan and who is not? Filming interactive conversations and situations was a fundamental methodology to comprehend the logic of exclusions or inclusion. Thus Goffman works (Goffman, 1959) remain very speakful for any scientific filmmaker. Who can be considered as a member of the Diaspora and who is excluded from the community? For Angie, being at the margin of the Diaspora was a way to personally incorporate the boundaries of Tibetan identity in opposition to the Indian and Punjabi personality. When we began the field research about "Women and Vulnerability" We did not interview Angie at first. It is the rest of the colony who used to narrate her life-story inviting us to be interested in her case study. The old women of the colony were concerned with her situation. Angie had a very young and half cast little girl called Peggy and a lot of difficulties to make a living. These edges were limits, frontiers but also interstitial spaces that the camera stressed as highly symbolical of the edges between the Tibetan enclave and the Punjabi market. As a filmmaker, from France, we filmed the intersection and the myriad of boundaries. Filming was like mapping the Diaspora in its geographical context but it was also an operation piling up various dimensions. The economical, the social and psychological attributes were all part of successive layers of frontiers. Even the name Angie was a point of intersection. The Indian community used to call her Angu (Angoo is an Indian name), the Tibetan named her Pema (Lotus in Tibetan language) or Angie. These plural designations are illustrating her cross-cultural habits from going to the Tibetan enclave to the Punjabi zone. Angie is a paradigm of cultural hybridism from below. Born in India her first partner was Indian from the Punjab zone who gave her two children. The film is

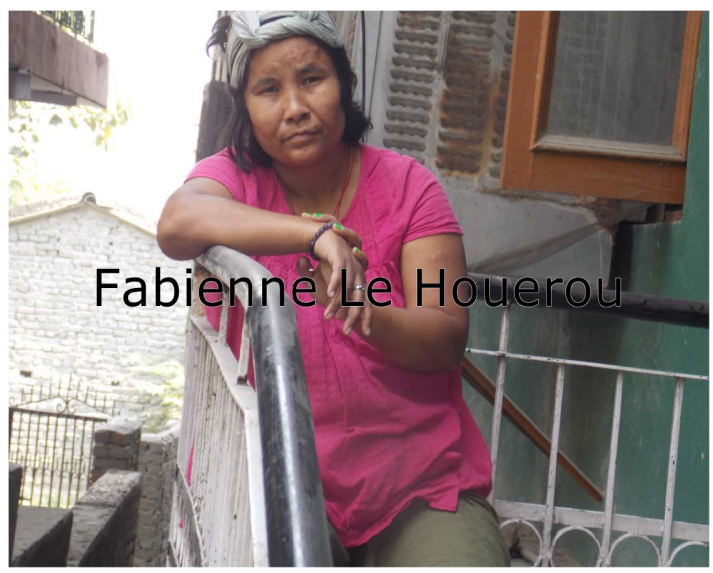

Figure 10. is portraying Angu/Angie, a Tibetan refugee who was the main character of the ethnographic film "Angu a Woman on the Edge". Credit photo Fabienne Le Houérou, 2013. 
difficult to classify. We could name it a scientific film with "ethnographic intentions" (Ruby, 1996). The documentary is telling the story of a marginal woman in exile in India and her social destiny with an African partner. The purpose is based on Homi Bahba theoretical orientations and theories on hybridity and mixity. How far a cross-marriage is tolerated by the Tibetans in exile in India in the urban enclave of Majnu Ka Tilla? The film is an attempt to answer a theoretical question and, in this perspective, can be classified as a film with an ethnographic ambition which does not neglect to emphasize on the emotions of two exiled souls (Le Houérou, 2016).

\section{Conclusion}

Punjab migrants have a stronger sense of what is a "dirty" person and soul. This sense of impurity is an essential boundary: an ethnic and religious distinction (Barth, 1969). Symbolic boundaries are traced according to notions of purity or impurity. The bridge is thus a frontier for the Tibetan enclave separating and linking the Tibetans with the ancient Punjab colony. The first immigrants of the Punjab colony facing the Tibetan colony, behind the bridge, were first inhabited by Punjab refugees coming from Pakistan during the partition of India in the late forties. Nowadays, in 2018, all these first inhabitants have passed away and Punjabi Basti is populated by varied groups including people from Rajasthan and the descendants of the first Punjabi immigrants. Thus this zone of North Delhi is a suburb populated by internal and external displaced. We could consider that geographically the Tibetans are the most visible groups. They are recognizable with the Tibetans colored praying flags that are clear markers and urban signals telling that the buildings are Tibetans. The bridge is also enveloped-as we have seen-in our pictures by such religious flags. Tibetan tradition states that when the wind blows in the flags, slowly moving with the flow all the wishes, of the one who attached the flags will be fulfilled. In ten years I have always witnessed the religious flags moving with the wind marking the territory humanly and religiously. This Tibetan tradition is like and identity outcry or shout telling the whole world "we are Tibetans".

It is using a classical anthropological methodology that we could apprehend the ethnic frontiers (Barth, 1969). The precise moment in which a Tibetan looses his identity and melts into the Indian society by filming the streets interactions and the process of becoming an Indian. The process starts by living outside the Tibetan enclave. Many Tibetans who cannot afford the rising rents of the Tibetan enclave (due to hotels and tourist activities) are forced to live in the Punjabi Basti where renting an apartment is half the price and sometimes three time less expensive. Living in Punjabi zone is seen as an economical and social decline influencing a cultural and identity loss. To Melt with the Punjabi population is perceived as a risk "of identity loss", and forgetting your Tibetan culture, an informant declared that he "was fearing to live in the Punjab zone and becoming dirty, throwing garbage on the roads and losing his Tibetan behavior". 
These frontiers are mental, social and religious and cannot be recognized with self-photography. The acculturation process is transparent through participant observation. As we have seen participant observation is a very ancient ethnographic technique adopted at the early age of the discipline.

This traditional methodological tool was essential to comprehend the limits of Tibetanhood and the piling dimensions of this identity as successive layers. It is through classical ethnographic filming methodology that we apprehended the plural edges and the crucial social Tibetan rules of solidarity. Filming one single marginal woman was much more heuristic than interviewing many other members of the Diaspora. The ways she was rejected by others was much more significant about what was truly Tibetan than the pictures of folkloric scenery that they auto-produced.

Facebook, WhatstApp, Wechat, which (as the reader could see) can be seen as a revolution on self picturing and auto-photography stressing that the use of disposal cameras is-as far as methodology is concerned-outdated. Smartphones have completly changed the representation of self and communication among the refugees communities, is, like everywhere else in our global world, largely based on exchanging images, gif, short movies, easy to read on mobiles telephones.

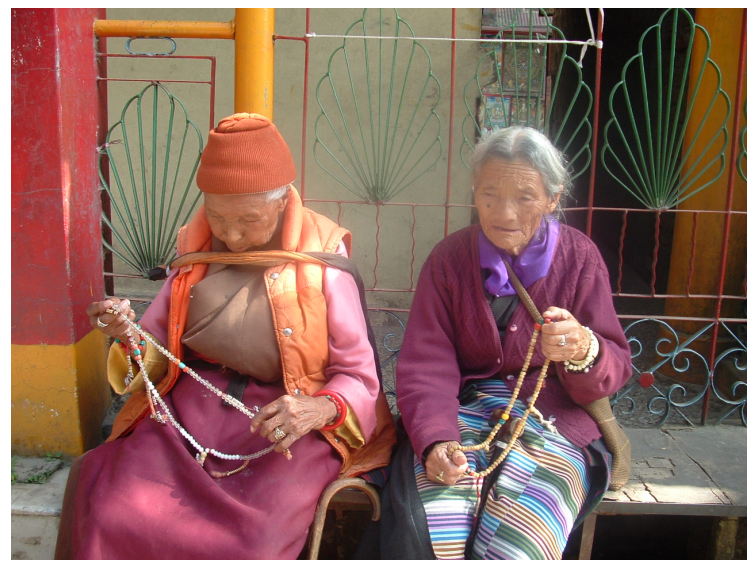

\section{References}

Bahba, H, (2004). The Location of Culture (p. 408). New York, London: Routledge Classics.

Barth, F, (1969). Ethnic Groups and Boundaries, The Social Organization of Culture Difference (p. 153). Long Grove, IL: Waveland Press Inc.

Fournier, B., Bridge, A., Mill, J., Alibhai, A., Kennedy, A. P., \& Konde-Lule, J. (2014). Turning the Camera Back: A Photovoice Project with Ugandan Children Who Are Orphaned and Living with HIV. Sage Open, 2014, 1. https://doi.org/10.1177/2158244014530997

Goffman, E, (1959). The Presentation of Self in Every Day Life (p. 259). New York: Anchor Book.

International Campaign for Tibet (2007). Dangerous Crossing: Conditions Impacting the Flight of Tibetans Refugees. Washington. 
https://www.savetibet.org/tibet-brief-edition-04-august-2007/

Le Houérou, F. (2008). Interview of the Tibetan Minister of Information in Dharamsala. Unpublished.

Le Houérou, F. (2010). Genre exil et persécutions, Revue Science and Video, 2.-Les Sabots Roses du Bouddha [Documentary]. Aix-en-Provence: CNRS Images Mai 2010.

Le Houérou, F, (2014). Humanitarian Crises and International Relations 1959-2013. Bentham Science: Sharjah. http://ebooks.benthamscience.com/book/9781608058341/ https://doi.org/10.2174/97816080583411140101

Le Houérou, F, (2016). Filmer les réfugiés. Paris: L'Harmattan.

Portes, A, \& Wilson, K. L. (1980). Immigrant Enclaves: An Analysis of the Labor Market Experiences of Cubans in Miami. The American Journal of Sociology, 86, 295-319. https://doi.org/10.1086/227240

Rigzin, T. (2015). A Survey Research on Tibetan Entrepreneurs in India, MDP. Atlanta, GA: Emory University.

http://www.nyamdel.com/wp-content/uploads/2014/07/report-on-Tibetan-Entreprene $\underline{\text { urs }}$

Ruby, J, (1996). Visual Anthropology. In: Levinson \& M. Ember (Eds.), Encyclopedia of Cultural Anthropology (pp. 1345-1351), New York: Henry Holt and Company.

Thomas, M. E. (2009). Auto-Photography. Columbus, OH: Ohio State University. https://booksite.elsevier.com/brochures/hugy/SampleContent/Auto-photography.pdf

Wang, C., \& Burris, M. (1997). Photovoice Concept, Methodology, and Use for Participatory Needs Assessment. Health Education \& Behavior, 24, 369-387.

https://doi.org/10.1177/109019819702400309

Wang, C., \& Redwood-Jones, Y. A. (2001). Photovoice Ethics: Perspectives from Flint Photovoice. Health Education \& Behavior, 28, 560-571.

https://doi.org/10.1177/109019810102800504 


\section{WEB}

http://tibet.net/2009/04/world-wide-demographic-survey-of-tibetans-in-exile-begins-12-a pril, http://self.gutenberg.org/articles/eng/1959_Tibetan_exodus, https://en.wikipedia.org/wiki/Tibetan_diaspora 